Chirurgia (2021) 116: 238-247

No. 2, March - April

Copyright@ Celsius

http://dx.doi.org/10.21614/chirurgia.116.2.238

\title{
The Remodeling in Advanced Breast Cancer Radiotherapy
}

\section{Ion Christian Chiricuță*}

AMETHYST Radiotherapy Center, Otopeni, Romania

${ }^{*}$ Corresponding author:

Professor Ion Christian Chiricuță AMETHYST Radiotherapy Center Otopeni, Romania

E-mail: kirikuta@gmx.de

\section{Rezumat \\ “Remodeling” în radioterapia cancerului de sân avansat}

Datorită progreselor realizate în domeniul imagisticii, a caracterizării tumorilor şi a tratamentelor disponibile (chirurgie mai radicală şi radioterapie cu technici moderne), noi oportunități au apărut în tratamentul cazurilor local avansate de cancer mamar. Procesul de "remodeling" este acum o realitate şi obținerea controlului tumoral local prin administrarea locală de doze de iradiere mai ridicate fără a avea efectele secundare este posibilă. Conceptul de volum țintă şi technicile moderne de radioterapie cu intensitate modulată (IMRT) permit aplicarea distribuției dozelor conforme volumului țintă favorizând "remodeling"-ul țesuturilor: în tumoră şi în patul tumoral la nivelul parților moi sau la nivelul tesutului osos sau chiar cerebral. În această lucrare prezentăm cazuistica personală în care procesul de "remodeling" a fost realizat la nivelul peretelui toracic, la nivelul coloanei vertebrale, a bazinului osos şi chiar la nivelul sistemului nervos central.

Cuvinte cheie: remodeling, cancer de sân, volum țintă, radioterapie

\section{Abstract}

New concepts had to be developed since the progress in diagnostic methods, tumor characterization and progress in treatment delivery (more aggressive surgery and radiotherapy) made possible new approaches for locally advanced breast cancer. The process of remodeling is now a reality and the local cure of locally advanced tumor by only high dose radiotherapy is now 
possible. Based on modern irradiation techniques as IMRT, VMAT or Tomotherapy, target volume conformal dose distributions delivered to complex targets made possible the "remodeling" process at the soft and/or bone tissue. We present from our own experience clinical cases of "remodeling" at the level of chest wall and bone metastases at the spine and pelvic bone.

Key words: remodeling, advanced breast cancer, target volume, radiotherapy

\section{Introduction}

The treatment of advanced breast cancer patients is a subject of debates in the last decades. In the late decades the complex treatment included surgery, chemotherapy, hormontherapy and radiotherapy. New concepts had to be developed since the progress in diagnostic methods, tumor characterization and progress in treatment delivery (more aggressive surgery and radiotherapy) made possible new approaches for locally advanced breast cancer.

In the last decades tumor imaging by introduction of computer tomography (CT), magnetic resonance imaging (NMR) and of the of positron emission tomography (PET/CT) made possible a real progress in radiotherapy. From the 2D radiotherapy which was a standard routine breast cancer radiotherapy a transition to the $3 \mathrm{D}$ radiotherapy was possible. The high frequency of acute and late side effects to the normal structures around the real target volume (the breast tissue, chest wall, and lymphatic areas as axilla, internal mammary chain and supraclavicular lymph nodes) made necessary new developments. The most important step forward was realized by the introduction of the concept of the anatomical defined clinical target volume (CTV) which included the microscopical disease, the gross tumor volume which included the macroscopic visible tumor (GTV). The normal tissues around the above defined target volumes were the loco-regional lymphatics (axillary nodes, internal mammary chain node and the supraclavicular lymphatics), the brachial plexus, the lung tissue and the myocard and the ribs are well visualized. The concept of target volumes and real advanced conformal radiotherapy to apply the necessary curative dose to the CTV and GTV and to reduce the dose delivered to the organs of risk was developed and routinely applied in the late eighties by the team conducted by professor W. Bohndorf at the University of Würzburg, Germany. The initial concept of target volume definition was published by E Richter and W. Bohndorf in the 1986 (1). The development of conformal irradiation techniques to cover the CTV and GTV and to reduce the applied dose to the organs at risk was realized by the department of medical physics conducted by J. Richter (2) (Fig. 1).

In the last decades by the systemic treatments important progress what 5 years
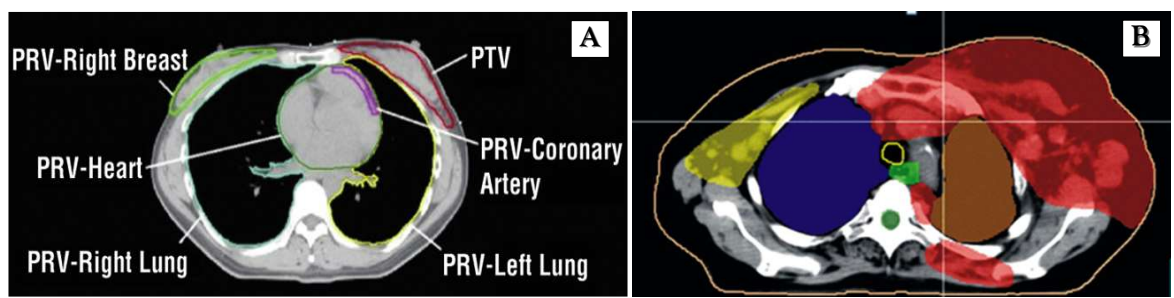

Figure 1. PTV (planning target volumes) (A) (2) and CTV (B) and GTV (C) and the organs at risk (middle and right side) for advanced breast cancer radiotherapy

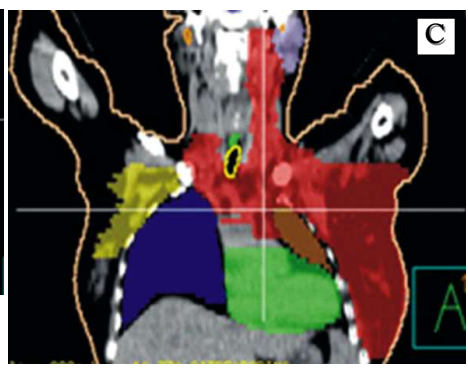


Metastatic breast cancer: improved survival over time

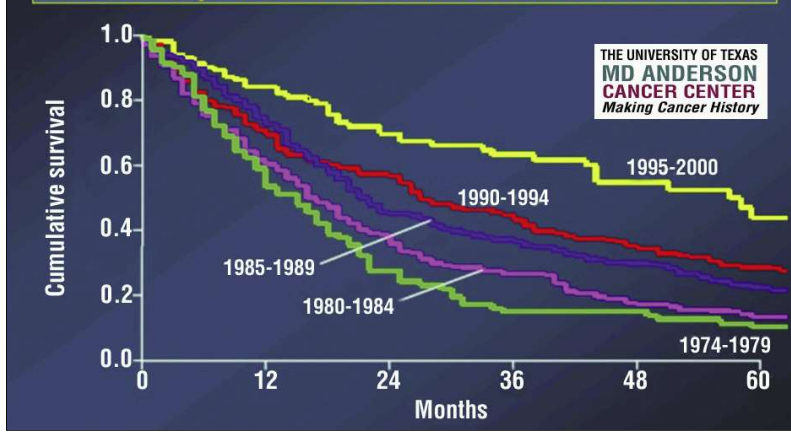

Figure 2. Advances in the treatment of advanced breast cancer patients (3).

Adapted after Giordano et al. Proc ASCO 2002

survival concern was realized in the treatment of metastatic breast cancer as is shown in the Fig. 2. Patients with long term survival could profit from radiotherapy to local or systemic tumor control.

The scope of the treatment of locally advanced breast cancer is to offer a local tumor control that is only obtained by delivery of large total dose to the GTV (more than 66 - 70 Gy in standard fractionation) and 50 -56 Gy to the CTV and a low dose to the organs at risk.

\section{Remodeling, Cellular Aspects at the Level of the Extracellular Matrix}

The influence of ionizing radiation at the tumor tissue and cell level and the processes of reducing the side effects of radiation are schematically represented in the Fig. 3. At the top of the image are represented the 4 phases of the healing process of lesions produced by surgery or radiotherapy namely the phase of hemostasis, inflammatory phase, proliferative phase and the remodeling phase.

At the bottom of the image are shown schematically the biological processes as a result of the action of radiation on the tumor DNA and due to double-stranded lesions that are irreversible, which finally facilitates the destruction of tumor cells by initiating the process of cell death called apoptosis. This explain how local tumor control is possible. Optimizing this process of tumor destruction and restoring the structures of the peritumoral tissue makes possible the remodeling process in which the healing process is present.

The role of the extracellular matrix and cellular regulators in the plasticity of tumor cells are schematically rendered in the Fig. 4.

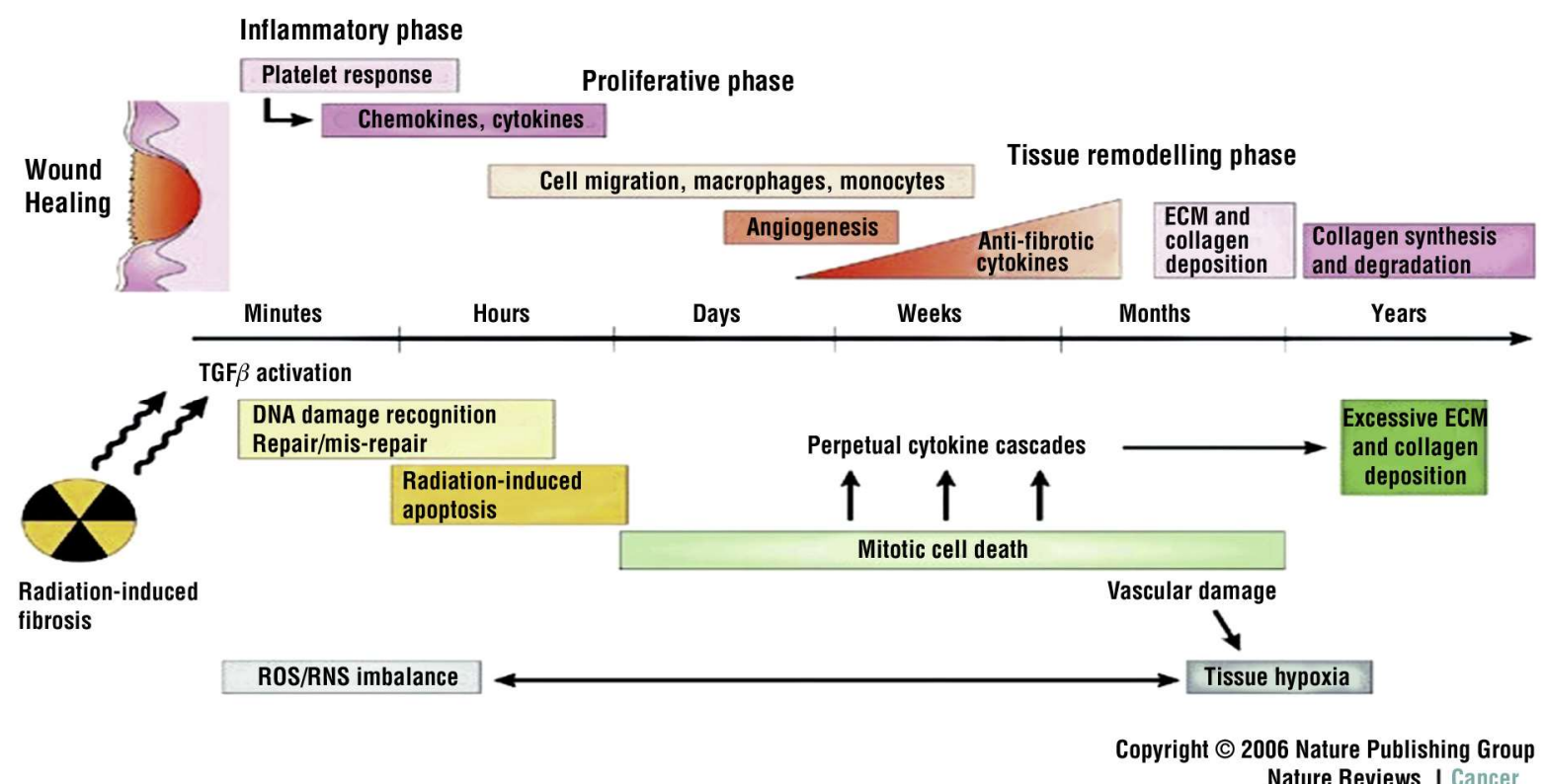

Figure 3. Schematic representation of radiation action at the tumor cell level (at the bottom) and of the remodeling and scarring process (at the top of the figure) (4) 
$\mathrm{A}$

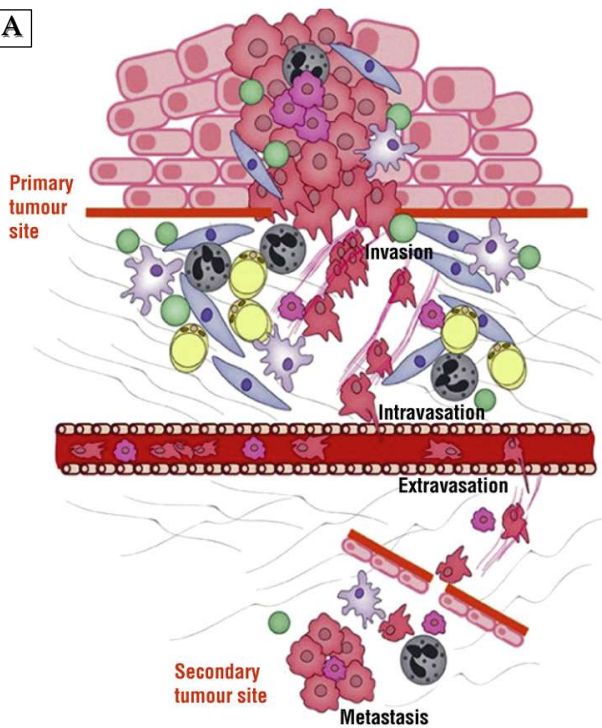

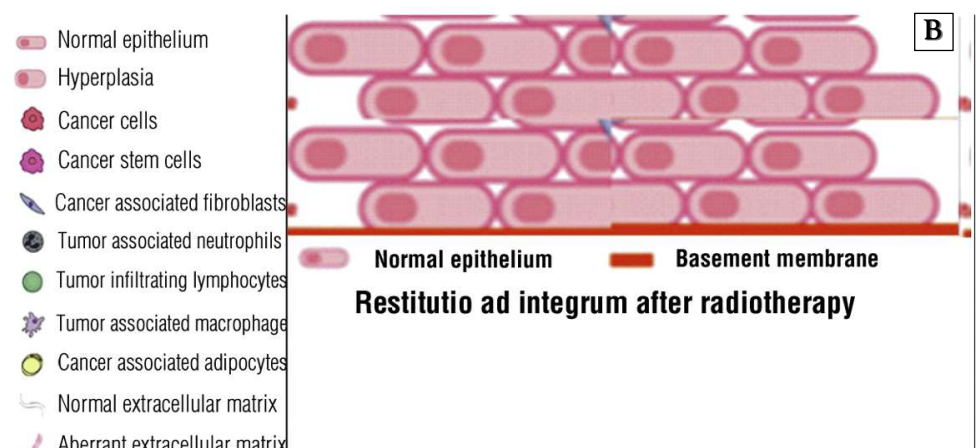

Figure 4. Schematic representation of pathophysiological processes that demonstrate the cellular plasticity of tumor cells in the invasion process with tumor progression and metastasis (A) (5) and restoration of the basal membrane and epithelium after tumor destruction by irradiation (B)
The destruction of the tumor following irradiation makes possible to restore the basal membrane and sometimes even remodeling with restitutio ad integrum in the tumor bed is possible.

Tissue restoration ad integrum after destruction of malignant tumor and restoration of the basal membrane is shown in Fig 4.

\section{Wound Healing and Tissue Repair Process}

The complexity of the "healing" after surgery and tissue repair process after radiotherapy with the representation of the 4 phases of healing that are partially overlapping is shown in the figure (Fig. 5) (6).

\section{"Remodeling" at the Vascular Level of Malignant Tumors}

The local tumor progression is also facilitated by the production of a new vascularization with "neogenesis vessels" as shown in Fig. 6. The neoformation vessels have an increased permeability that facilitates the process of remote metastasis. At the tumor level occur several processes such as angiogenesis, lymph angiogenesis, vascular permeability and all the consequences of these processes (tumor
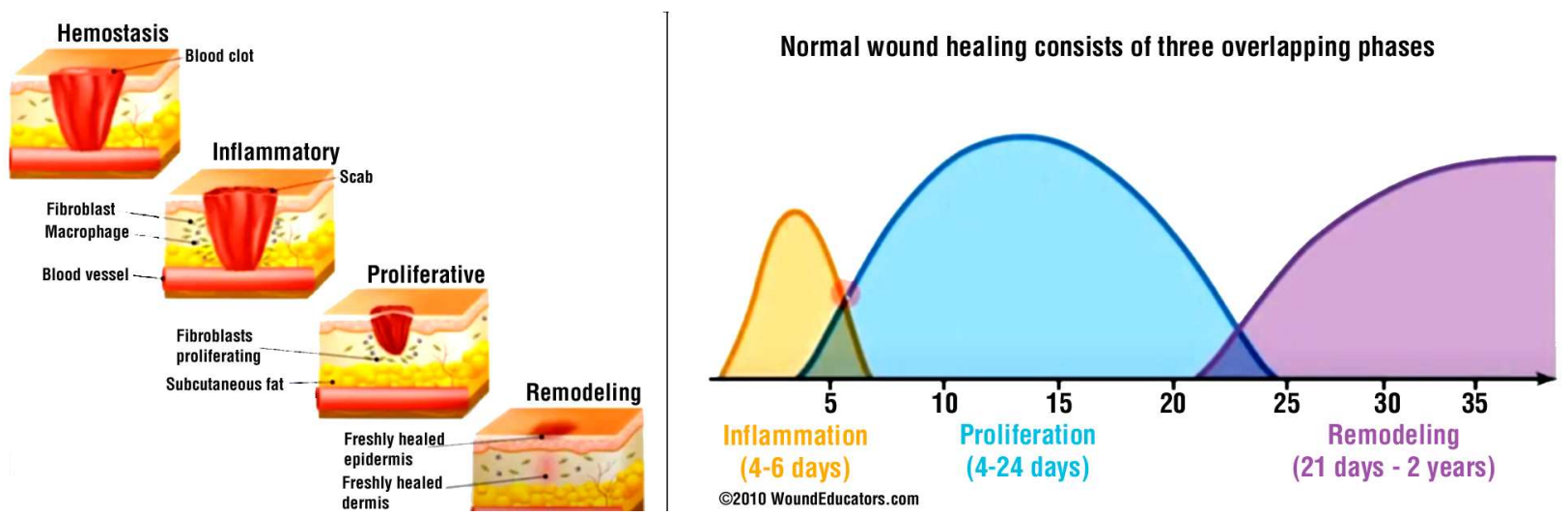

Figure 5. Stages of the process of healing after surgery and radiotherapy with their overlapping (on the time scale): inflammatory phase, proliferation and tissue remodeling with collagen accumulation in the terminal phase. (Maynard J. How wounds heal: the four main phases of wound healing. Shield Health Care 2015). 


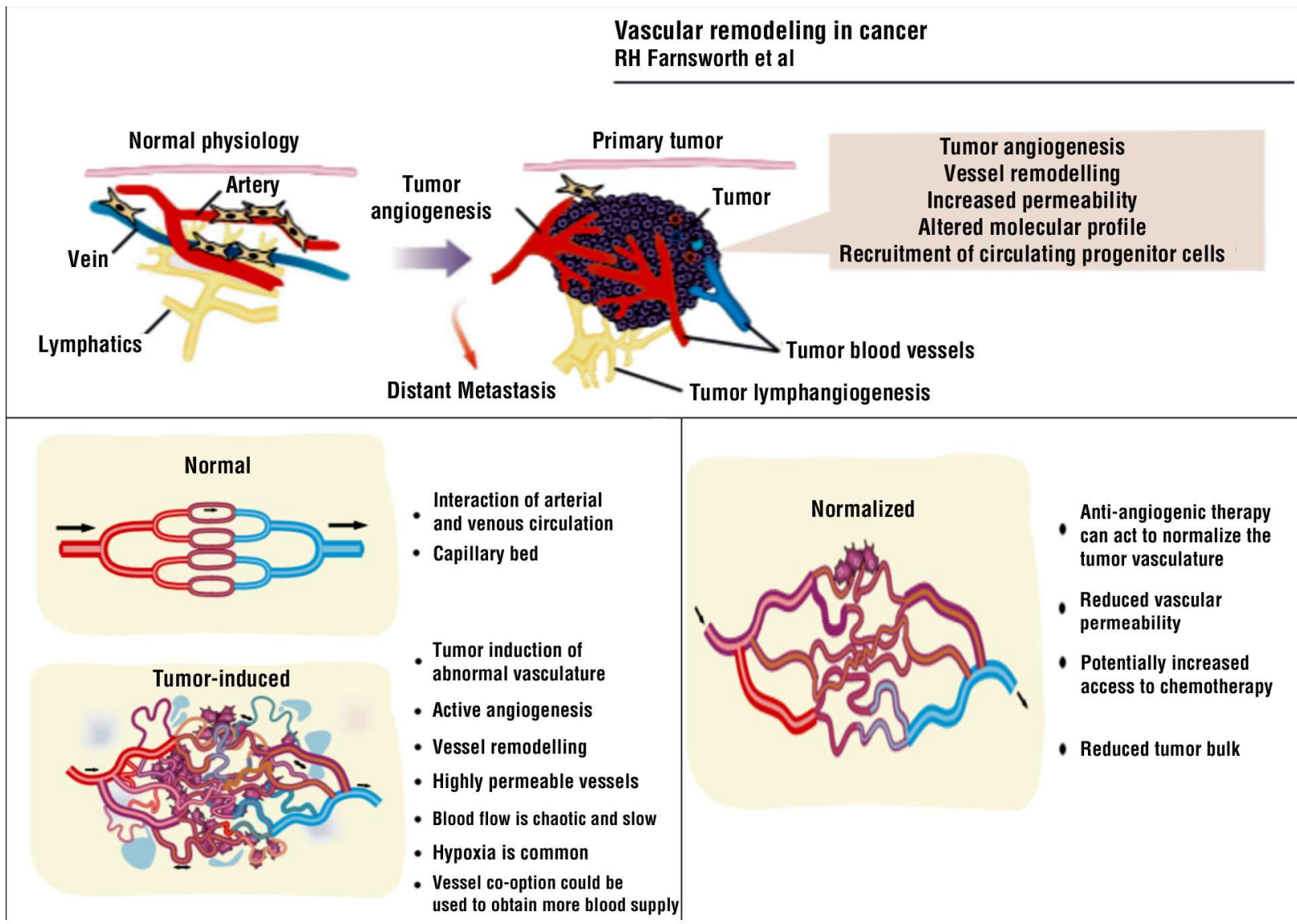

Figure 6. Processes induced at the tumor vascular level and the possible vascular "normalization" through therapy (chemotherapy and radiotherapy) (7)

hypoxia, vascular fragility, aggressiveness).

The action of radiotherapy at the level of tumor vascularization allows "a normalization" i.e. a vascular "remodeling" with all the advantages resulting from it (better oxygenation of tissues, more efficient action of cytostatics and radiation, reduction of hemorrhages).

\section{Clinical Aspects of the "Remodeling" Process}

\section{Locally advanced breast cancer}

We present here the clinical situation of a local advanced breast cancer in a women aged 82 who presented in our department and was treated by a conformal 10 fields radiotherapy (Fig. $\lambda$ ).

This case demonstrates the "remodeling" ability that exists in healthy tissues surrounding the tumor bed. In this case the healing action was completed by macrophages and fibroblasts present at this level. The action of fibroblasts has contributed to the collagen formation process to be present and to make possible "remodeling" at this level of all the structures initially involved: skin, ribs, pericardium, sternum, etc. Visible is the presence of extensive area of collagen in the extensive scarr. In the healing process the role of macrophages was the removal of damaged tumor cells by the double-strand lesion at the level of tumor DNA. There was no pulmonary fibrosis that usually accompanies post-radiotherapy healing. If a large volume of healthy tissue around GTV and CTV volume was not included in the planning volume, then it is not included in the healing process.

The final decision and finding the best solution for each individual patient cannot be limited by a "suboptimal" guideline and an incomplete "professional education". 
Figure 7. The clinical case of a local advanced breast cancer with sternal infiltration and internal mammary chain lymph node involvement before and after high dose radio-therapy. Upper line: clinical response to a high total dose of 72 Gy. Lower line: (left: in the primary series a total dose of $50 \mathrm{~Gy}$ in 25 fractions) was applied and (right): with an additional boost of $22 \mathrm{~Gy}$ in $2 \mathrm{~Gy}$ fractionation.

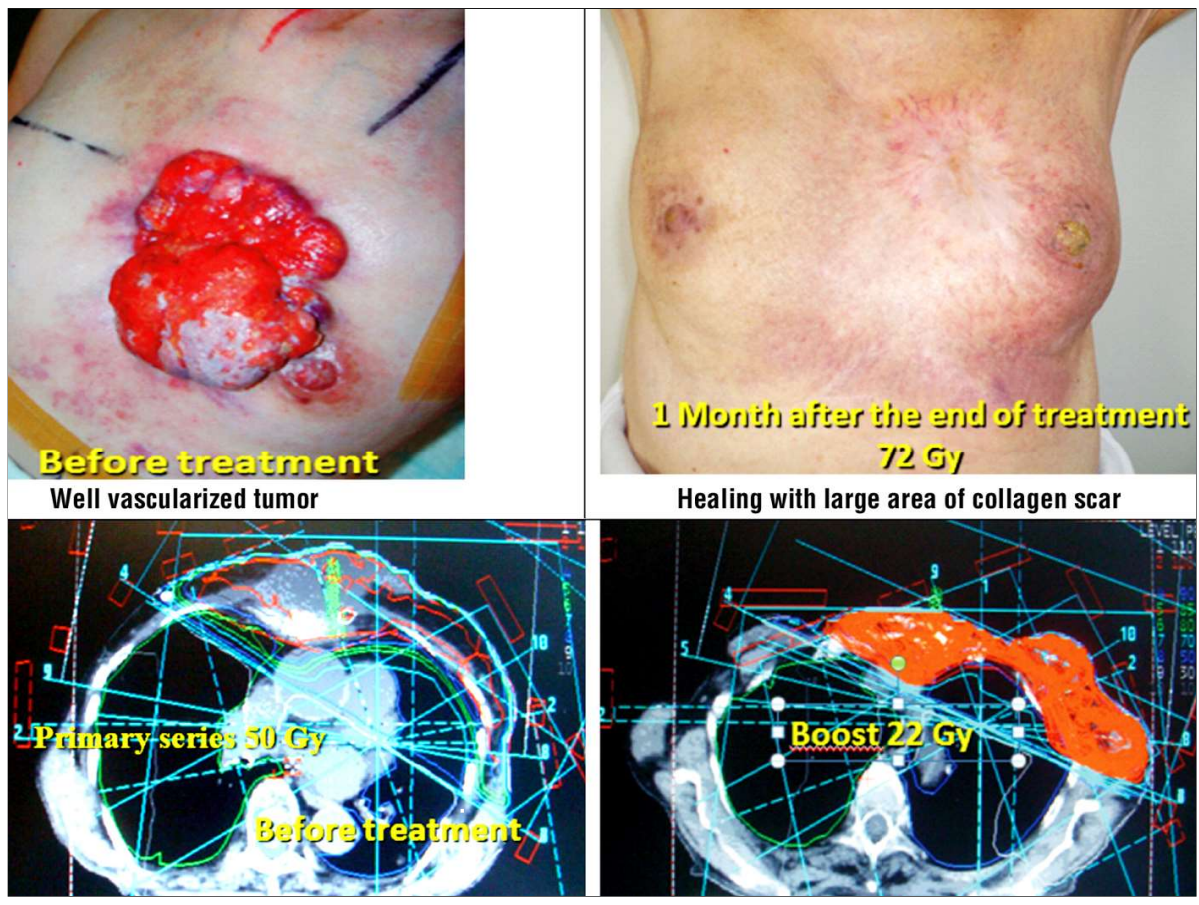

\section{Bone metastases}

A patient with bone metastases throughout the skeleton and taking advantage of radiotherapy with standard doses of 2 Gy per fraction and total doses to achieve tumor control over years is presented. A survival of almost four years was possible. The primary tumor in the breast was treated by surgery followed by adjuvant chest wall radiotherapy in 1979. The first bone metastasis was irradiated in 8/1993 and the last palliative radiotherapy was applied in 5/1997 (Fig. 8).

Bone metastasis and processes in the extracellular $\underline{\text { matrix }}$

Cellular processes at the level of a bone metastasis: initiation (after homing of tumor cells at the bone level) of osteoclasts are activated with local metastatic progression and followed by remodeling at the extracellular matrix level by activating post therapeutic osteomacs.

\section{The process of remodeling facilitated by initiating the radiotherapy of bone metastasis}

With the location of the tumor cell in the bone, begins the process of damaging its compact structure. Stromal and pro-inflammatory cells recruited by tumor cells such as macrophages, neutrophils, T cells and mastoid cells produce and release many mediators that act on osteoblasts, osteoclasts and nerve endings at this level. The most important is the endotelin which initiates the process of stimulating osteoblasts that releases the socalled RANKL which is an activator that initiates the maturation and proliferation of the osteoclasts. Osteoclasts promote demineralization, destruction and bone lysis. They stimulate macrophages to produce pro-inflammatory cytokines (TNF-alpha, ILß and IL6) and pain-inducing prostaglandins by binding them to receptors in neuronal sensors (Fig. 9 ).

All therapeutic interventions must be individualized and directed in order to reduce pain so an improvement in the quality of life should be achieved, and thus facilitate to prolongation of life with longer survival. Only by reducing pain will not achieve an improvement in survival, this action must also be sustained by a total destruction of the tumor itself. A single dose of 8 Gy applied to a single bone metastasis to a vertebral body will bring a reduction in pain but the patient will not have a longer survival if the metastasis itself 
Figure 8. Irradiated regions of the bone skeleton in a patient with a breast tumor who survived 4 years with radiation therapy

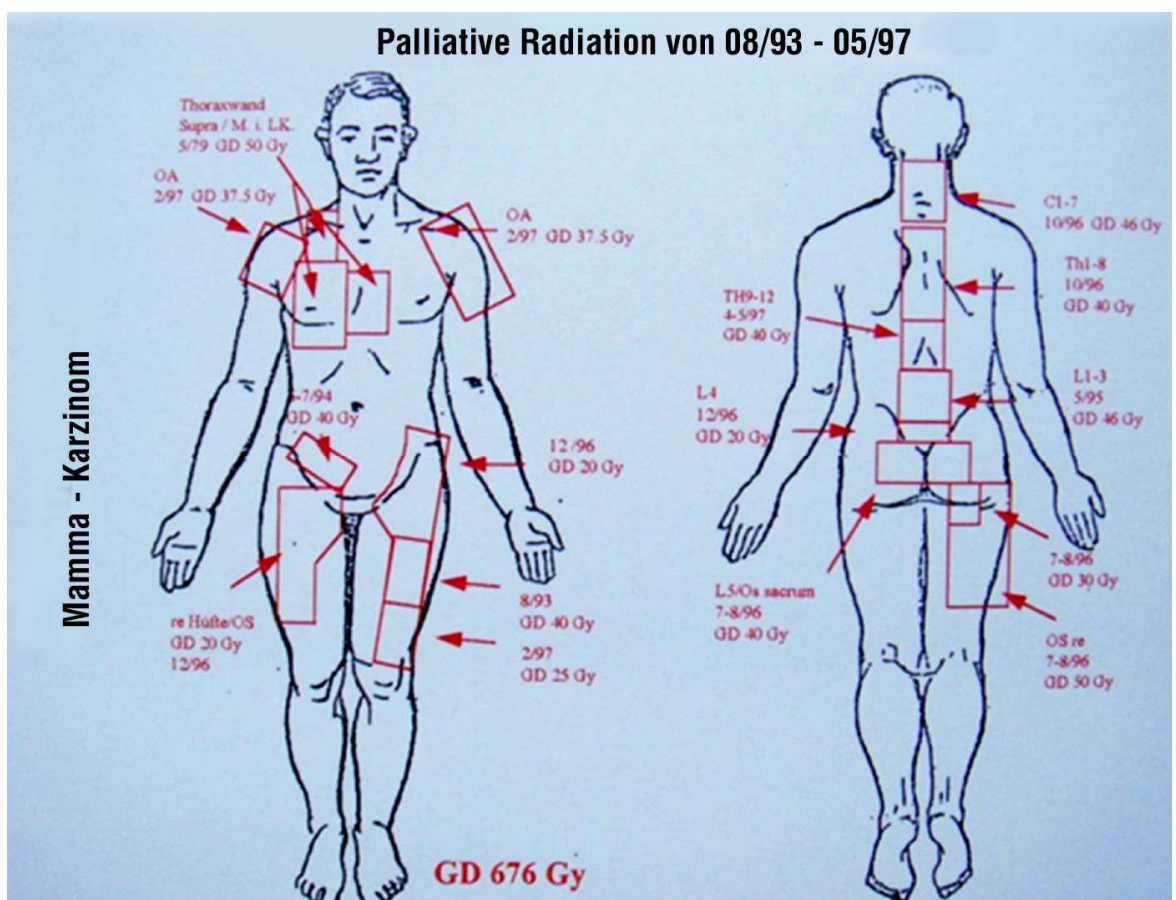

is not destroyed, which with only 8 Gy cannot be achieved. The possible right treatment could be the application of an initial dose of 8 Gy, that makes it possible to reduce pain and continue irradiation with fractional doses of 2 or 3 Gy up to a total dose equivalent to $40 \mathrm{~Gy}$ at the level of spinal cord, a dose that also allows the destruction of tumor cells.
This kind of "mistake" is too common done in clinical activity since the misunderstanding of the differentiated action of high single doses, that can lead to pain control (success rate of $45 \%$ ) but only for lasting few days. "Improved quality of life for only a few days" is paid for by subsequent death, due to the insufficient dose applied to control the tumor itself for years.
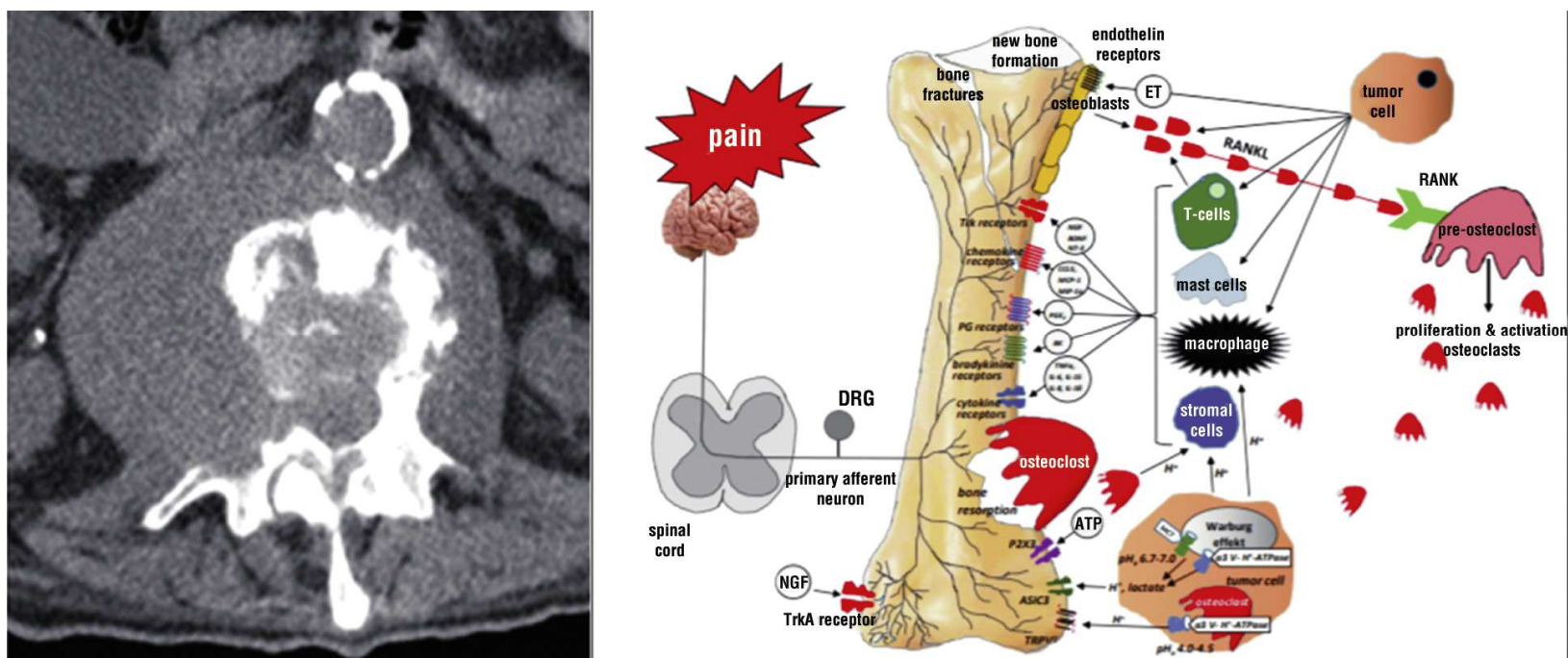

Figure 9. On the left: bone metastasis with the destruction of the vertebra (breast cancer) and with the invasion of the paravertebral muscle (treated at an oncology center with a single fraction of 8 Gy). Subsequently the patient died with only this distant metastasis. On the right: mechanisms from the initiation of bone metastasis (activation of osteoclast) followed by osteolysis and the mechanism of central pain transmission (8) 


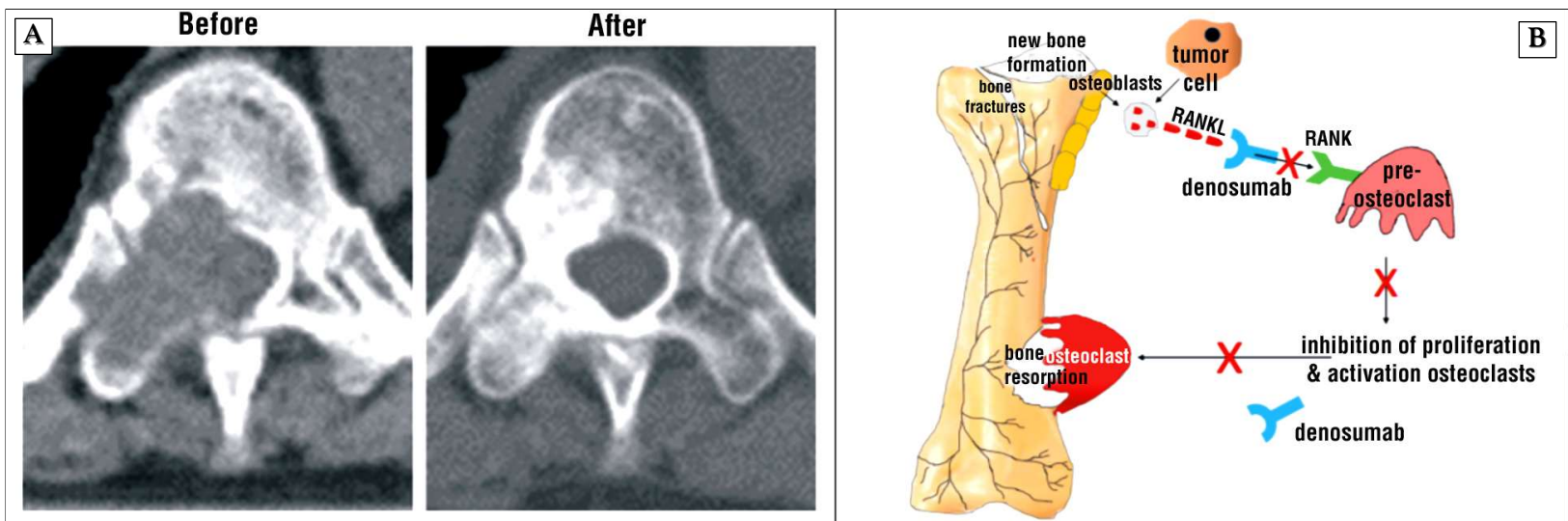

Figure 10. (A) Complete remodeling of a vertebral metastasis. Improvement of osteolytic metastasis from a vertebral body after administration of zoledronic acid and external radiotherapy with 28 Gy in 7 fractions. (B) The role of the RANKL/RANK system and the mechanism of action of Denosumab in bone pain. $X=$ stop (9)

Bone remodeling is a continuous process initiated by the action of radiotherapy or/and bisphosphonate on osteoclasts and thus allows osteoblasts to initiate the remodeling phase with bone formation especially at the periosteum and endostal level. Here it should be remembered the importance of the action of the macrophage at this level called osteomacs which has the most important role in the "remodeling" of the bone. It should be remembered that in general the skeletal system has the capacity to maintain the stability and functional malleability of the entire bone system and that annually $10 \%$ of the bone system is renewed. So in 10 years we take advantage of a "physiological" remodeling and maintenance of our entire bone system.

An example for this kind of combined treatment with zoledronic acid and a fractional radiotherapy applied to a metastasis in a vertebral body that affected the stability of the spine is shown in Fig. 10. The clinical result of this combined treatment in which the total dose in that fractionation allowed to stop the action of osteoclasts and initiate osteomacs activity with the final result of "remodeling" and healing of the vertebral body using the initial matrix of the vertebral body is shown in Fig. 10.

\section{Multiple bone metastasis with bone destruction}

Patients with multiple pelvic bones metas- tases could profit from a whole pelvic bone radiotherapy as shown in Fig. 11 . The patient was irradiated with a 2 Gy daily fraction to a total dose of 40 Gy. The protection of organs at risk as bladder, small bowel, rectum and sigmoid was possible. Multiple lytic bone lesions and complete destruction of the acetabulum were present. Two years later all bone lesions and the acetabulum destruction were in complete restitution as shown in the Fig. 11 .

Radiation therapy of multiple bone metastases and complete destruction of the right coxo-femoral joint of a breast cancer in the bone pelvis. Restitutio ad integrum of all

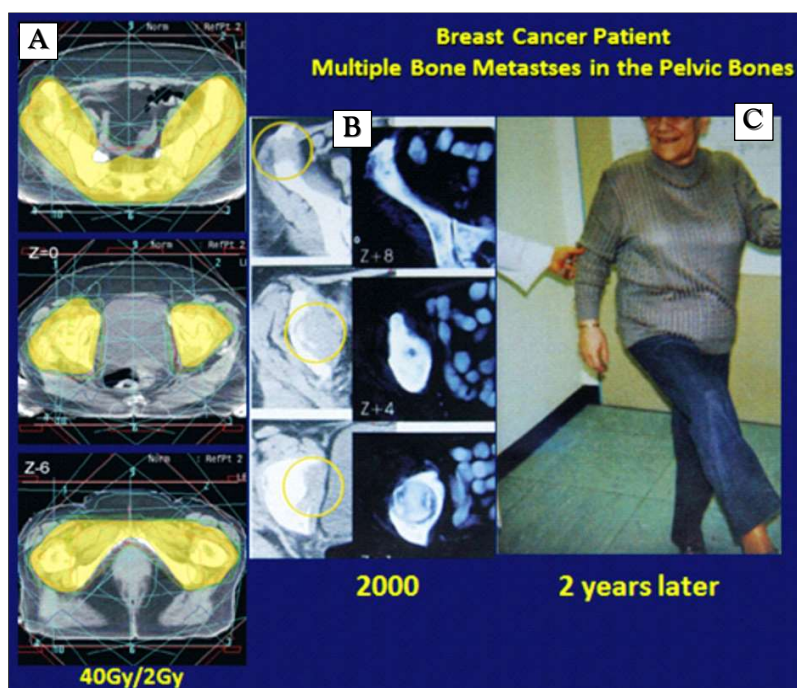

Figure 11. Dose distribution of the whole pelvic bone radiotherapy (A), bone reconstruction after radiotherapy (B) and clinical situation 2 years later (C) 


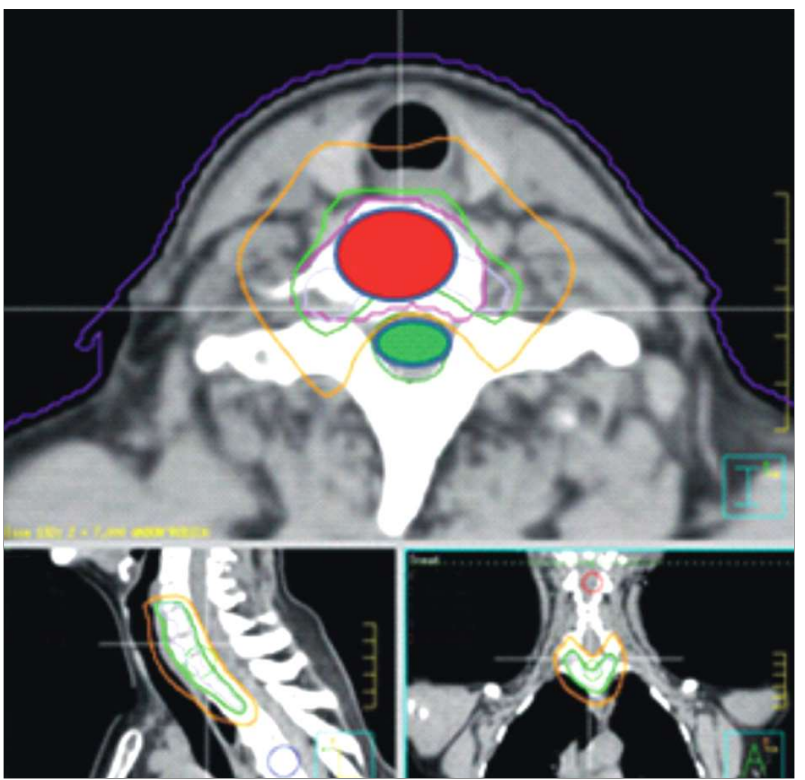

Figure 12.

Reirradiation of 4 cervical vertebral bodies with the protection of the spinal cord

bone metastases and especially of the right coxo-femoral joint with the restoration of acetabulum was possible.

\section{Reirradiation of vertebral bone metastases}

In Fig. 12 it is shown the planning using for the VMAT (Volume Modulated Arc
Therapy) irradiation used for the reirradiation of 4 cervical vertebral bodies of a local recurrence after a palliative radiotherapy applied by a dorsal field to a total dose of $3 \mathrm{X}$ 5 Gy. On the spinal cord the total dose was limited to $20 \mathrm{~Gy}$ in 10 fractions of $3 \mathrm{~Gy}$ applied to the cervical vertebral bodies as shown in the Fig. 12.

\section{Irradiation of vertebral metastases}

Restoration of the shape of the thoracic vertebra after surgery and postoperative radiotherapy of a bone metastasis of a breast cancer in the thoracic spine at the level of T11 is shown in Fig. 13.

In the images below can be observed osteolysis produced by tumor cells located in the vertebral body at the beginning of the endosteal and the action of osteoclasts and destruction of the periosteum has compromised completely the stability of the vertebrae. In this case 10 fractions of $3 \mathrm{~Gy}$ were applied, which made possible to initiate the remodeling process and through the action of osteomacs and osteoblasts appeared "the new" remodeled bone that followed exactly the initial matrix of the vertebral body being thus

Before (A) and after (B) radiotherapy of the metastatic vertebra with the restoration of the initial shape of the vertebral body.

Irradiation plane of the thoracic vertebra T11 with the spinal cord protection. Dose applied: 30 Gy in 10 fractions.
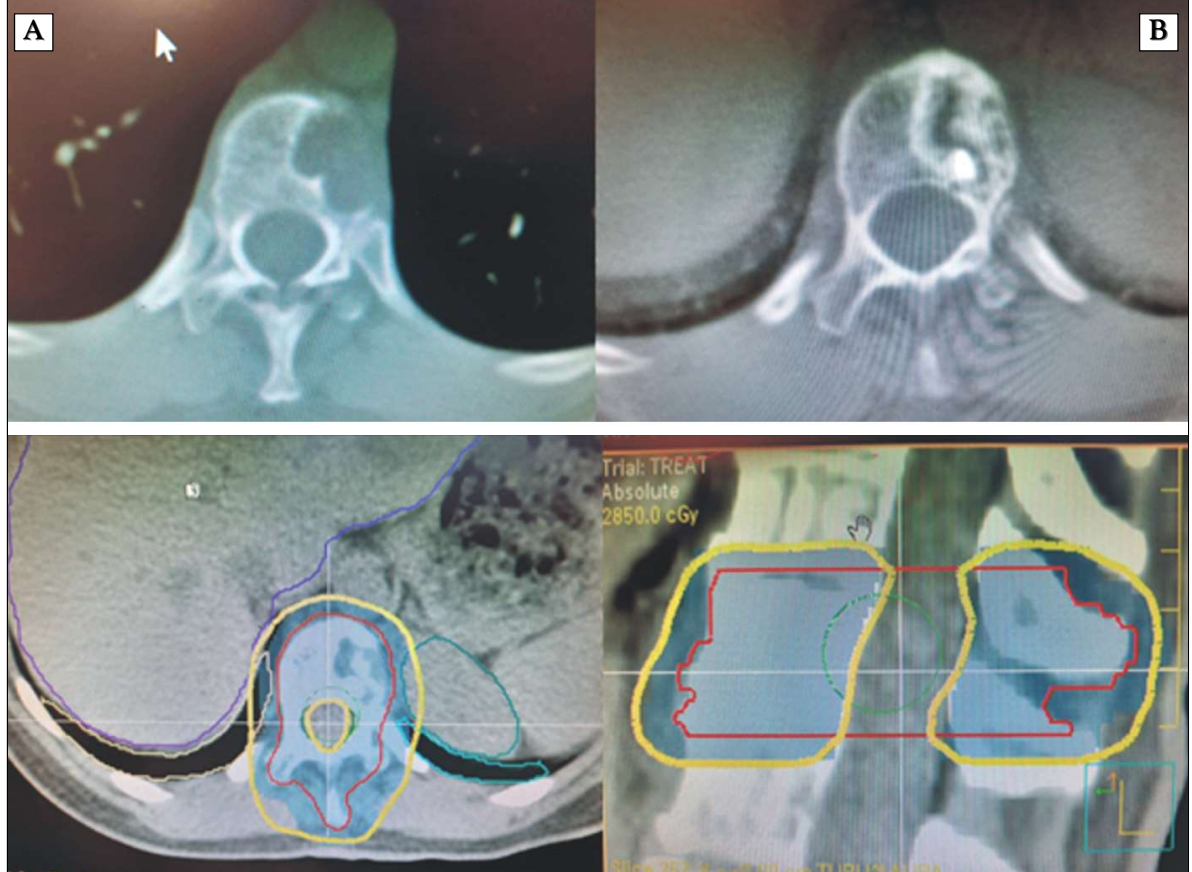

Figure 13. Evolution and irradiation plan of a vertebral body metastasis 
Figure 14. Whole brain radiotherapy (A) with concomitant boost to the macroscopic metastatic disease (B).
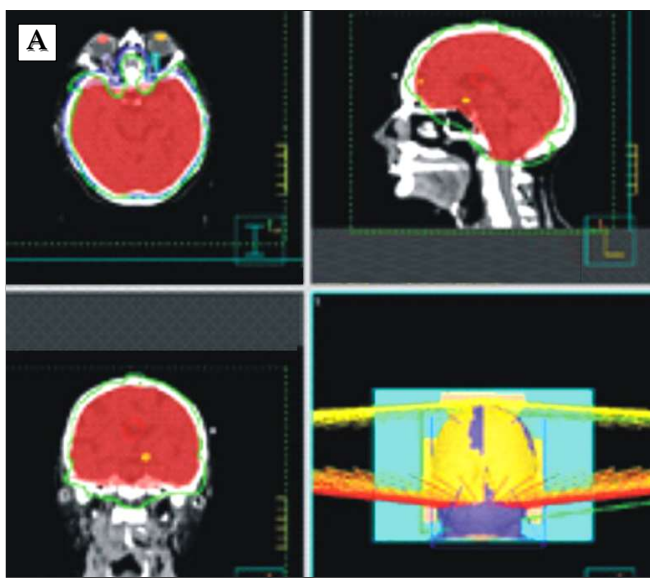

possible ad integrum reconstruction of the final shape of the vertebral body after radiotherapy.

\section{Brain Metastases}

In case of multiple brain metastases we use a combination between a whole brain radiotherapy with a concomitant boost to the metastatic sites so at the end of 10 fractions of 3 Gy to the whole brain the total dose of $30 \mathrm{~Gy}$ and in the boost area 39 Gy were applied (Fig. 14). The remodeling of the initial neurological deficit was possible.

\section{Conclusion}

The progress in radiotherapy is a result of improved imaging methods (CT, MRI, PET/ CT) and as well as developed planning and dose delivery methods as VMAT, Rapid Arc and Tomotherapy techniques based on individually defined target volumes. Optimal dose delivery to CTV and GTV and limited dose delivery to organs at risk as lung parenchyma, brachial plexus, myocardial tissue and axillary vessels is now possible. Higher tumor control rates with less acute and late side effects make now possible the improvement of the quality of life.

\section{Conflict of Interest}

The author declare no conflicts of interests.

Ethics Approval: it is not research.

\section{References}

1. Judge $\mathrm{E}$, Bohndorf W. Target volume determination with $\mathrm{CT}$ in pharynx and larynx tumors. Radiot \& Oncolog. 1986;162:162-70.

2. Jin GH, Chen LX, Deng XW, Liu XW, Huang $Y$, Huang XB. A comparative dosimetric study for treating left-sided breast cancer for small breast size using five different radiotherapy techniques: Conventional tangential field, Field-in-field, Tangential-IMRT, Multi-beam IMRT and VMAT. Radiat Oncol. 2013:8:89.

3. Giordano SH, Buzdar AU, Smith TL, Kau SW, Yang Y, Hortobagyi GN. Is breast cancer survival improving. Trends in survival for patients with recurrent breast cancer diagnosed from 1974 through 2000. Cancer. 2004;100(1):44-52.

4. Bentzen SM. Preventing or reducing late side effects of radiation therapy: radiobiology meets molecular pathology. Nat Rev Cancer. 2006;6(9):70213.

5. Poltavets V, Kochelkova M, Pitson M, Samuel MS. The role of extracellular matrix and its cell regulators in cancer cells plasticity. Front. Oncol. 2018;8:article 431:1-19.

6. Lali FV, Metcalfe AD. The role of angiogenesis in wound healing, scarring and tissue regeneration. PMFA News. 2014;2(1):1-4.

7. Farnworth RH, Lackermann M, Achen MG, Stacker SA. Vascular remodeling in cancer. Oncogene. 2014;33(27):3496-505.

8. Krisnawan VE, Stanley JA, Schwarz JK, DeNardo DG. Tumor micro-environment as a regulator of radiation therapy: new insides into the stromal-mediated radiorezistance. Cancer. 2020:12:2916-41.

9. Tanaka H, Makita CH, Manabe $\mathrm{Y}$, Kajima M, Matsuyama K, Matsuo M. Radiation therapy combined with bone-modifying agents ameliorates local control of osteolytic bone metastases in breast cancer. J Radiat Res. 2020;61(3):494-498. 